\title{
Expressão relativa do gene OsNPF7.4 em arroz é estimulada pelo fornecimento de nitrato em solução nutritiva
}

\section{Erika da Costa Fernandes ${ }^{1}$, Maria Eduarda Pimentel de Melo $^{2}$, Erinaldo Gomes Pereira ${ }^{3}$, Brisa Ribeiro de Lima ${ }^{3}$, Manlio Silvestre Fernandes ${ }^{4}$ e Leandro Azevedo Santos ${ }^{4}$}

\footnotetext{
${ }^{1}$ Universidade Federal Rural do Rio de Janeiro. Instituto de Agronomia. Programa de Pós-Graduação em Fitotecnia. Rodovia BR-465, km 07. Zona Rural. Seropédica-RJ, Brasil (CEP 23890-000).E-mail: erikac.fernands@gmail.com.

${ }^{2}$ Universidade Federal Rural do Rio de Janeiro. Instituto de Agronomia. Curso de Graduação em Agronomia. Instituto de Agronomia. Rodovia BR-465, km 07. Zona Rural. Seropédica-RJ, Brasil (CEP 23890-000).

${ }^{3}$ Universidade Federal Rural do Rio de Janeiro. Instituto de Agronomia. Programa de Pós-Graduação em Agronomia - Ciência do Solo. Rodovia BR-465, km 07. Zona Rural. Seropédica-RJ, Brasil (CEP 23890-000).

${ }^{4}$ Universidade Federal Rural do Rio de Janeiro. Instituto de Agronomia. Departamento de Solos. Rodovia BR-465, km 07. Zona Rural. Seropédica-RJ, Brasil (CEP 23890-000).
}

Resumo. $\mathrm{O}$ nitrato $\left(\mathrm{NO}_{3}{ }^{-}\right)$é a forma predominante de nitrogênio em solos bem aerados. Estudos recentes apontam a importância do gene OsNPF7.4 na eficiência de uso de $\mathrm{N}$ em arroz, atuando diretamente na multiplicação dos perfilhos. Entretanto, estudos de expressão desse gene sob variação no fornecimento de nitrato ainda são escassos. 0 objetivo do presente trabalho foi a caracterização da resposta deste gene frente a um período de supressão de nitrato $\left(\mathrm{N}^{-\mathrm{NO}_{3}}{ }^{-}\right)$de $72 \mathrm{~h}$. Plantas de arroz da variedade manteiga foram cultivadas em solução nutritiva por 30 dias e então submetidas a um período de supressão de $\mathrm{N}$ por $72 \mathrm{~h}$, seguido pelo reestabelecimento do nutriente. Foram realizadas coletas do tecido da bainha a cada $24 \mathrm{~h}$ no período de supressão e nos tempos 4, 8, 24 e 72 h após o ressuprimento e realizou-se análise da expressão relativa por PCR em tempo real. 0 gene OsNPF7.4 apresenta duas isoformas, derivadas de splicing alternativo. Com a análise da expressão relativa foi observado um decréscimo dos níveis de resposta das duas isoformas do gene no período de supressão de $\mathrm{N}$ e um pico de expressão logo após o ressuprimento. Estes resultados confirmam a alta dependência deste gene quanto a presença de $\mathrm{NO}_{3}{ }^{-}$na solução e indicam sua possível atuação no influxo de nitrato.

Palavras-chave: Nitrato; Influxo; Transportador NPF.

Recebido

$11 / 01 / 2021$

Aceito

$07 / 06 / 2021$

Disponível on line

$27 / 06 / 2021$

Publicado

$31 / 08 / 2021$

Acesso aberto

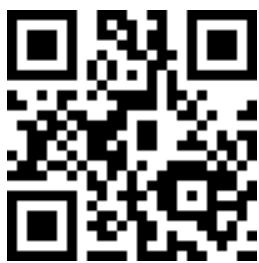

ISSN 2359-1412/RBGAS-2021-0001/2021/8/19/10/803

Rev. Bras. Gest. Amb. Sustent.

http://revista.ecogestaobrasil.net 


\begin{abstract}
Relative expression of OsNPF7.4 gene is stimulated by nitrate supply. Nitrate $\left(\mathrm{NO}_{3}^{-}\right)$is the predominant form of nitrogen in well-aerated soils. Recent studies show the importance of OsNPF7.4 gene on $\mathrm{N}$ use efficiency in rice, acting directly in the tillering. However, the characterization of this gene expression under different conditions of nitrate supply is still scarce. The aim of this study was to characterize the response of OsNPF7.4 to a nitrate $\left(\mathrm{N}^{-} \mathrm{NO}_{3}{ }^{-}\right)$suppression period. Rice plants, "manteiga" variety was cultivated in nutrient solution subjecting them a $\mathrm{N}$ suppression for $72 \mathrm{~h}$, followed by the reestablishment. The sheaths were collected every $24 \mathrm{~h}$ during the suppression period and 4, 8, 24 and $72 \mathrm{~h}$ after resupply. Then real time PCR analysis was used to study its relative expression. The gene OsNPF7.4 has two isoforms originated by alternative splicing. Relative expression reveals that both of them show a decrease in the response of transcription after suppression of $\mathrm{N}$ (succeeding) followed by an increase after resupply. These results confirm the high dependence of this gene (regarding) on the presence of $\mathrm{NO}_{3}$ in solution and indicate its possible performance in nitrate influx.
\end{abstract}

Keyword: Nitrate; Influx; NPF transporter.

\author{
ORCID \\ (1) 0000-0003-2960-1881 \\ Erika da Costa \\ Fernandes \\ (D) 0000-0002-7701-4166 \\ Maria Eduarda \\ Pimentel de Melo \\ (D) 0000-0002-9052-091X \\ Erinaldo Gomes \\ Pereira \\ (D) 0000-0001-5168-4797 \\ Brisa Ribeiro de Lima \\ (D) 0000-0001-5329-6122 \\ Manlio Silvestre \\ Fernandes \\ D 0000-0002-2595-9432 \\ Leandro Azevedo \\ Santos
}

\section{Introdução}

O arroz Oryza sativa L. é um grão de elevado potencial agrícola por todo o mundo, sendo essencial para a alimentação humana. O Brasil se destaca como o único país nãoasiático entre os 10 maiores produtores do mundo (FAO, 2019). Por ser uma cultura tão importante economicamente, estudos de melhoramento genético são necessários buscando elevar cada vez mais sua produtividade agrícola.

Um dos fatores que afetam diretamente esta produtividade é a nutrição mineral, onde se destaca o nitrogênio $(\mathrm{N})$. $\mathrm{O} \mathrm{N}$ é um macronutriente essencial para o pleno desenvolvimento e crescimento vegetal. Tal característica é proveniente da sua participação na constituição de ácidos nucleicos e proteínas, além de sua presença em ciclos como o do carbono (C) e até mesmo na fotossíntese. Em razão disso a eficiência de uso de nitrogênio (EUN) é uma das características mais importantes utilizadas na avaliação da produtividade das plantas. A EUN pode ser dividida em eficiência de absorção, assimilação e utilização (Han et al., 2015). A eficiência de absorção é a capacidade das plantas em transportar o nutriente do solo para dentro das células, ou seja, de absorver o nutriente. Compreender a funcionalidade dos transportadores é uma estratégia importante para melhorar essa característica nas plantas e consequentemente reduzir a permanência dos nutrientes no solo, reduzindo as perdas para o ambiente.

$\mathrm{O} \mathrm{N}$ é encontrado na solução do solo em diversas formas, sendo uma delas o nitrato $\left(\mathrm{NO}_{3}{ }^{-}\right)$que é predominante em solos aerados (Williams e Miller, 2001). $0 \mathrm{NO}_{3}{ }^{-}$é absorvido contra o gradiente de potencial eletroquímico da célula necessitando de uma proteína transportadora do tipo simporte que o transloca juntamente com dois prótons para dentro da célula. Após a absorção o $\mathrm{NO}_{3}$ - pode ser assimilado em esqueletos de carbono no citosol ou enviado ao vacúolo celular para armazenamento e posterior assimilação, passando por duas etapas de redução, o que ocorre de acordo com a necessidade e disponibilidade energética da planta (Souza e Fernandes, 2018).

A absorção e movimentação do nitrato nas células depende de proteínas transportadoras altamente específicas que são divididas em alta afinidade (HATS - High 
afinity transporter system) que realizam o transporte em concentrações abaixo de $1 \mathrm{mM}$, denominadas NRT2 e baixa afinidade (LATS - Low affinity transporter system) que atuam em concentrações maiores que $1 \mathrm{mM}$ pertencentes a família NPF - Nitrate Transporter 1/Peptide Transporter (Léran et al., 2014).

A família NPF em arroz é extensa compreendendo um conjunto de 93 genes, entretanto apenas 11 destes foram funcionalmente caracterizados até o momento (Huang et al., 2019). Dentre eles, sete apresentam splices alternativos OsNPF2.4, OsNPF6.3, OsNPF7.1, OsNPF7.4, OsNPF7.7, OsNPF8.9 e OsNPF8.20 e todos mostraram-se envolvidos na eficiência de absorção de nitrogênio e determinação da produtividade de grãos (Lin et al., 2000; Fang et al., 2013; Xia et al., 2014; Wang et al., 2018; Huang et al., 2018; 2019).

0 gene OsNPF7.4 (antigo OsPTR5) foi caracterizado recentemente e apontado como regulador antagônico ao OsNPF7.1 (antigo OSPTR4), atuando como bloqueador na formação ou alongamento das gemas axilares e no controle do número de perfilhos em arroz. Além disso, apresenta papel importante participando na alocação de $\mathrm{N}$ das raízes para as folhas, influenciando o crescimento e desenvolvimento de plantas de arroz (Huang et al., 2019). Todavia, poucas informações foram disponibilizadas quanto à expressão das diferentes isoformas desse gene, suas respostas frente ao fornecimento de nitrato e sua localização subcelular, características essas que determinam sua atuação na planta.

0 estudo da expressão do gene frente a períodos de flush de nitrato nos permite esclarecer a funcionalidade do gene no metabolismo de $\mathrm{N}$ e levantar hipóteses quanto à sua atuação no transporte do íon. Diante do exposto, o objetivo do presente trabalho foi identificar os níveis de resposta do gene OSNPF7.4 em plantas de arroz submetidas à supressão de $72 \mathrm{~h}$ e posterior ressuprimento do fornecimento de nitrogênio na forma de nitrato $\left(\mathrm{N}-\mathrm{NO}_{3}-\right.$ ).

\section{Material e métodos}

Foi realizada uma busca da sequência do gene no banco de dados de arroz, a plataforma Rice Genome Annotation Project (http://rice.plantbiology.msu.edu/). Foram encontradas duas isoformas do gene OSNPF7.4, disponíveis, a sequência CDS das duas isoformas foram então, utilizadas para desenho dos primers e realização da PCR em tempo real.

Tabela 1. Sequências dos primers utilizados na análise da expressão relativa por PCR em tempo real das isoformas do gene OsNPF7.4.

\begin{tabular}{|l|l|l|l|}
\hline \multicolumn{1}{|c|}{ Gene } & \multicolumn{1}{|c|}{ Foward } & \multicolumn{1}{c|}{ Reverse } & Acession number \\
\hline OsNPF7.4 sp1 & TTCTTCTGGGCATGTCGGC & GACACGACCGTCTTCACCTT & LOC_Os04g50940.1 \\
\hline OsNPF7.4 sp2 & CCCAAACTTTGAACTTGATCTGC & GCACTCGAATCCTAGCACCA & LOC_Os04g50940.2 \\
\hline OsUBQ5 & ACCACTTCGACCGCCACTACT & ACGCCTAAGCCTGCTGGTT & LOC_Os01g22490.1 \\
\hline
\end{tabular}

0 experimento foi realizado em câmara de crescimento com plantas de arroz (var. manteiga). As sementes foram desinfestadas em solução de hipoclorito de sódio 2,5\% e transferidas para potes com gaze contendo somente água destilada. Seis dias após a germinação, as plântulas foram transferidas para vasos de $0,7 \mathrm{~L}$, dispostos em delineamento inteiramente ao acaso, contendo quatro plantas por vaso que receberam solução nutritiva de Hoagland (Hoagland e Arnon, 1950) modificada com 1/2 força iônica, utilizando $5 \mathrm{mM}$ de $\mathrm{CaNO}_{3}$ e pH 5,5. Esta solução foi trocada a cada três dias.

Aos 30 dias após a germinação foi realizada a primeira coleta, denominada tempo zero e utilizada como controle. Em seguida a solução nutritiva foi substituída por uma solução sem fornecimento de nitrogênio, para caracterizar o período de supressão de $\mathrm{N}$. 
Esta foi mantida por três dias realizando-se uma coleta por dia, sempre às 9:00 h. No terceiro dia a solução nutritiva foi substituída reestabelecendo o fornecimento de nitrogênio com $5 \mathrm{mM}$ de $\mathrm{NO}_{3}$ - e então foram coletadas amostras nos tempos 4, 8, 24 e $72 \mathrm{~h}$ após o ressuprimento.

As plantas coletadas foram separadas em folha, bainha e raiz, pesadas para obtenção da massa fresca, retirada uma amostra e armazenada em freezer $-80{ }^{\circ} \mathrm{C}$ para posterior extração do RNA total, que foi realizada de acordo com Gao et al. (2001). Após extração, as amostras foram tratadas com DNAse utilizando o kit "Amplification Grade DNAse I" da Sigma ${ }^{\circledR}$. Em seguida foi realizada a construção da fita de DNA complementar (cDNA) com o kit "High Capacity RNA-to-cDNA" da Life Technologies ${ }^{\circledR}$, seguindo as recomendações do fabricante.

As reações de PCR em tempo real foram feitas utilizando o kit "5x HOT FIREPol EvaGreen ${ }^{\circledR}$ qPCR Mix Plus (ROX) (Solis Biodyne) de acordo com as recomendações do fabricante no equipamento "StepOne Plus Real-Time PCR System" (Applied Biosystems). Os cálculos de expressão relativa foram realizados de acordo com Livak e Schmittgen (2001) a partir dos valores de CT (Cicle Thereshold, ciclo limite) obtidos na reação de PCR em tempo real, utilizando a ubiquitina 5 (OsUBQ5) como gene de referência e o tratamento do tempo zero como controle. A construção dos gráficos foi realizada utilizando o programa Sigmaplot 12.5 .

\section{Resultados e discussão}

O gene OsNPF7.4 apresenta duas isoformas nos bancos de dados disponíveis para arroz, decorrentes de splicing alternativo. A análise de expressão das duas isoformas possibilita elucidar a resposta do gene à disponibilidade de $\mathrm{NO}_{3}{ }^{-}$em solução. A isoforma 1 (OsNPF7.4 sp1, Figura 1A), apresentou baixa expressão durante todo o período de supressão de $\mathrm{N}$ que perdura até às $4 \mathrm{~h}$ após o ressuprimento $(76 \mathrm{~h})$. Entretanto, $8 \mathrm{~h}$ após o ressuprimento $(80 \mathrm{~h})$ há um aumento acentuado na transcrição que se reduz após $24 \mathrm{~h}$ (96 h).
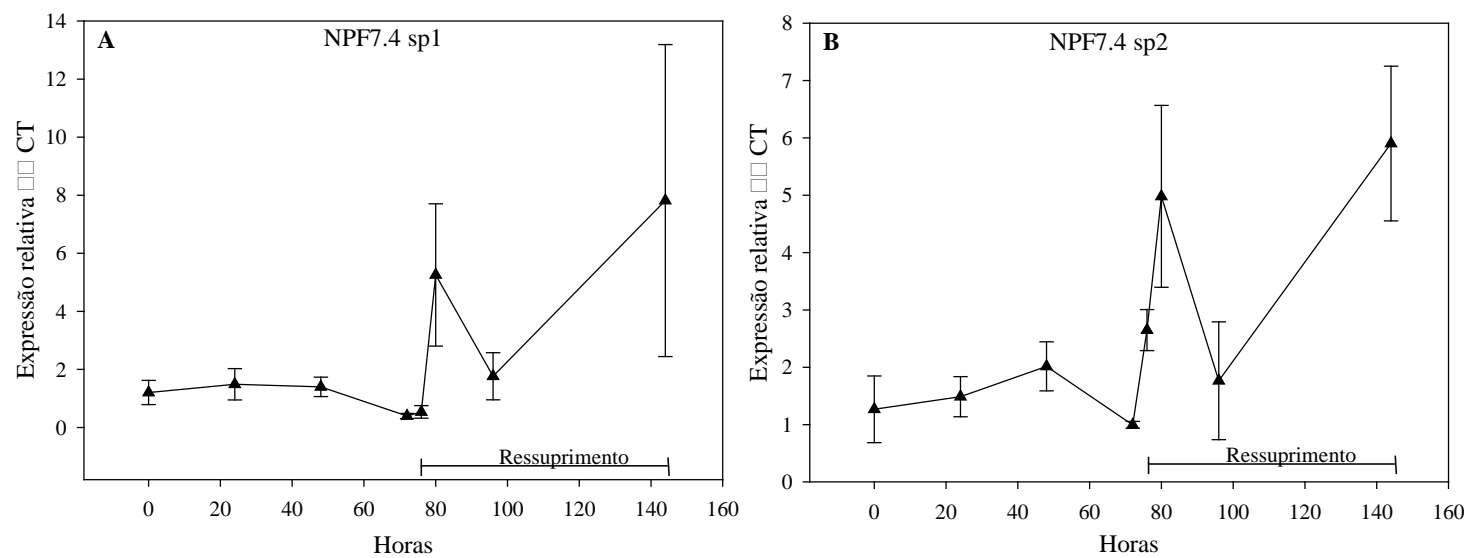

Figura 1. Expressão relativa das isoformas do gene OsNPF7.4 em plantas de arroz (var. Manteiga), submetidas a um período de supressão e ressuprimento de $\mathrm{N}-\mathrm{NO}_{3}$ - de 72 horas.

Por outro lado, a isoforma 2 (OsNPF7.4 sp2, Figura 1B) apresentou uma leve resposta de transcrição após $48 \mathrm{~h}$ de supressão de $\mathrm{N}$ caindo às $72 \mathrm{~h}$. Mas, com o ressuprimento há uma resposta rápida de transcrição, logo às 4 h (76 h) e que continua 
aumentando até às $80 \mathrm{~h}$ formando um pico de expressão. Esta rápida elevação de transcritos demonstra uma alta regulação deste gene pela a presença do íon nitrato na solução, sendo OsNPF7.4 sp2 de resposta rápida.

A rápida elevação nos transcritos logo após o fornecimento de nitrato em solução corrobora com os resultados encontrados por Huang et al. (2019), apontando que ambas as variantes deste gene são reguladas pela concentração de fontes externas de N. E levanta a possibilidade de atuação da proteína no influxo de nitrato, visto que a superexpressão das duas isoformas do gene OsNPF7.4 em arroz promoveu o influxo de $\mathrm{NO}_{3}$ - e reduziu a concentração do íon nas folhas, enquanto o nocaute do gene demonstrou resultado inverso (Huang et al., 2019). Entretanto estudos de localização subcelular são necessários para confirmar esta hipótese.

Quanto aos níveis de expressão podemos observar que OsNPF7.4 sp1 apresenta níveis ligeiramente mais elevados quando comparado ao OsNPF7.4 $s p 2$. Esta variação corrobora com a encontrada em trabalho recente que identificou OsNPF7.4 sp1 como mais expresso que $0 s N P F 7.4 s p 2$ durante o período de desenvolvimento vegetativo de arroz sob diferentes concentrações de $\mathrm{NO}_{3}$ - (Huang et al., 2019). Variações nos níveis de expressão entre splices do mesmo gene também foram encontrados para o gene OsNPF7.7 indicando diferentes funções de atuação do gene o que foi comprovado pela localização subcelular (Huang et al., 2018).

O splicing alternativo é um dos eventos que mais contribuem para a diversidade genética dos eucariotos e é uma das formas de enriquecer as funções dos genes (Graveley, 2001). Estudos recentes apontam que este fenômeno é muito comum em plantas, ocorrendo principalmente em resposta a mudanças climáticas (Cheng e $\mathrm{Tu}, 2018$ ). $\mathrm{O}$ conhecimento das variações alternativas de um gene bem como diferenças na expressão permite explorar suas funções e identificar as potencialidades de suas isoformas no metabolismo vegetal. Particularmente, no metabolismo de $\mathrm{N}$, genes com splicing alternativo têm demonstrado papel indispensável no transporte de nutrientes e na produtividade de plantas (Huang et al., 2018).

\section{Conclusões}

O período de supressão de $72 \mathrm{~h}$ foi suficiente para identificar variações dos níveis de resposta da expressão das duas isoformas do gene OsNPF7.4.

Foi constatada uma alta dependência do gene quanto a presença do íon $\mathrm{NO}_{3}$ - para sua expressão e a rápida resposta de transcrição dada pela sua presença o que relaciona este gene como um dos responsáveis pelo influxo de nitrato no vacúolo em arroz.

\section{Agradecimentos}

Todos os autores expressam profundo agradecimento à Coordenação de Aperfeiçoamento de Pessoal de Nível Superior (CAPES), ao Conselho Nacional de Desenvolvimento Cientifico e Tecnológico (CNPq), à Fundação de Amparo à Pesquisa do Estado do Rio de Janeiro (FAPERJ), pela concessão de recursos e da bolsa de estudos para o desenvolvimento do trabalho.

\section{Conflito de interesses}

Os autores declaram não haver conflito de interesses. 


\section{Referências}

Cheng, Y.; Tu, S. Alternative splicing and cross-talk with light signaling. Plant and Cell Physiology, v. 59, n. 6, p. 1104-1110, 2018. https://doi.org/10.1093/pcp/pcy114

Fang, Z.; Xia, K.; Yang, X.; Grotemeyer, M. S.; Meier, S.; Rentsch, D.; Xu, X.; Zhang, M. Altered expression of the PTR/NRT1 homologue OSPTR9 affects nitrogen utilization efficiency, growth and grain yield in rice. Plant Biotechnology Journal, v. 11, n. 4, p. 446-458, 2013. https://doi.org/10.1111/pbi.12031

FAO - Food and Agriculture Organization of the United Nations. Statistical databases. 2019. Disponível em: <http://www.fao.org>. Acesso em: 25 set. 2019.

Gao, J.; Liu, J.; Li, B.; Li, Z. Isolation and purification of functional total RNA from bluegrained wheat endosperm tissues containing high levels of starches and flavonoids. Plant Molecular Biology Reporter, v. 19, p. 185-186, 2001.

Graveley, B. R. Alternative splicing: Increasing diversity in the proteomic world. Trends Genetics, v. 17, n. 2, p. 100-107, 2001. https://doi.org/10.1016/S0168-9525(00)02176-4

Han, M.; Okamoto, M.; Beatty, P. H.; Rothstein, S. J.; Good, A. G. The genetics of nitrogen use efficiency in crop plants. Annual Reviews of Genetics, v. 49, p. 269-289, 2015. https://doi.org/10.1146/annurev-genet-112414-055037

Hoagland, D. R.; Arnon, D. I. The water-culture method for growing plants without soil. Berkley: University of California, 1950. (California Agricultural of Experiment Station, Circular 347).

Huang, W.; Bai, G.; Wang, J.; Zhu, W.; Zeng, Q.; Lu, K.; Sun, S.; Fang, Z. Two splicing variants of OsNPF7.7 regulate shoot branching and nitrogen utilization efficiency in rice. Frontier in Plant Science, v. 9, Article 300, p. 1-12, 2018. https://doi.org/10.3389/ fpls.2018.00300

Huang, W.; Nie, H.; Feng, F.; Wang, J.; Lu, K.; Fang, Z. Altered expression of OsNPF7.1 and OsNPF7.4 differentially regulates tillering and grain yield in rice. Plant Science, v. 283, p. 23-31, 2019. https://doi.org/10.1016/j.plantsci.2019.01.019

Léran, S.; Varala, K.; Boyer, J.-C.; Chiurazzi, M.; Crawford, N.; Daniel-Vedele, F.; David, L.; Dickstein, R.; Fernandez, E.; Forde, B.; Gassmann, W.; Geiger, D.; Gojon, A.; Gong, J.-M.; Halkier, B. A.; Harris, J. M.; Hedrich, R.; Limami, A. M.; Rentsch, D.; Seo, M.; Tsay, Y.-F.; Zhang, M.; Coruzzi, G.; Lacombe, B. A unified nomenclature of nitrate transporter 1/peptide transporter family members in plants. Trends in Plant Science, v. 19, n. 1, p. 5-9, 2014. https://doi.org/10.1016/j.tplants.2013.08.008

Lin, C. M.; Koh, S.; Stacey, G.; Yu, S. M.; Lin, T. Y.; Tsay, Y. F. Cloning and functional characterization of a constitutively expressed nitrate transporter gene, OsNRT1, from rice. Plant Physiology, v. 122, n. 2, p. 379-388, 2000. https://doi.org/10.1104/pp.122.2.379

Livak, K. J.; Schmittgen, T. D. Analysis of relative gene expression data using real-time quantitative PCR and the 2- ${ }^{-\Delta \Delta \mathrm{C}_{\mathrm{T}}}$ method. Methods, v. 25, n. 4, p. 402-408, 2001. https://doi.org/10.1006/meth.2001.1262

Souza, S. R.; Fernandes, M. S. IX- Nitrogênio. In: Fernandes, M. S.; Souza, S. R.; Santos, L. A. (Eds.). Nutrição mineral de plantas. 2. ed. Viçosa: Sociedade Brasileira de Ciência do Solo, 2019. p. 309-376. 
Wang, W.; Hu, B.; Yuan, D.; Liu, Y.; Che, R.; Hu, Y.; Ou, S.; Liu, Y.; Zhang, Z.; Wang, H.; Li, H.; Jiang, Z.; Zhang, Z.; Gao, X.; Qiu, Y.; Meng, X.; Liu, Y.; Bai, Y.; Liang, Y.; Wang, Y.; Zhang, L.; Li, L.; Sodmergen; Jing, H.; Li, J.; Chu C. Expression of the nitrate transporter gene OsNRT1.1A/OsNPF6.3 confers high yield and early maturation in rice. The Plant Cell, v. 30, n. 3, p. 638-651, 2018. https://doi.org/10.1105/tpc.17.00809

Williams, L. E.; Miller, A. J. Transporters responsible for the uptake and partitioning of nitrogenous solutes. Annual Review in Plant Physiology and Plant Molecular Biology, v. 52, p. 659-688, 2001. https://doi.org/10.1146/annurev.arplant.52.1.659

Xia, X.; Fan, X.; Wei, J.; Feng, H.; Qu, H.; Xie, D.; Miller, A. J.; Xu, G. Rice nitrate transporter OsNPF2.4 functions in low affinity acquisition and long-distance transport. Journal of Experimental Botany, v. 66, n. 1, p. 317-331, 2015. https://doi.org/10.1093/jxb/eru425 